\title{
POBREZA, EXCLUSIÓN SOCIAL Y DISCRIMINACIÓN ÉTNICO-RACIAL EN AMÉRICA LATINA
}

\author{
Leila Bijos*
}

\section{Resumén}

Reflexión acerca de las transformaciones económicas, la ausencia de políticas públicas y sociales para una población indígena, especialmente mujeres aymara, quéchua, moxeñas, niegras brasileñas, y de la Provincia de Bahia, descendientes de los esclavos africanos, excluídas socialmente. A pesar de los niveles de desarrollo alcanzados en las últimas décadas, América Latina posue todavía, una parcela significativa de su población viviendo en pobreza absoluta.

Palabras Claves: Género y Poder; Opresión; Exclusión Social; Discriminación ÉtnicoSocial; Racismo; Sexismo; Derechos Humanos;

\section{Introducción}

Durante las últimas décadas América Latina no fue contemplada con un deseo político y los gobernantes no presentaron reformas sólidas para disminuir los niveles de hambre y miseria. Las políticas incorrectas afectaron a las mujeres e impidieron su desarrollo social, privándolas de educación, una renta adecuada, de igualdad de género, justicia social y acesso a políticas públicas. El desarrollo no solamente genera crecimiento, sino también distribuye beneficios justos y de forma imparcial. Él empodera a la gente, especialmente a las mujeres, y prioriza beneficios para las pobres, ampliando sus oportunidades, eliminando la discriminación de género, insertándolas en el mercado de trabajo, para que inicien un negocio, a veces un micro negocio en el sector informal de la economía. El desarrollo proporciona la inserción de las mujeres en una sociedad masculina, donde ciertas formas de racismo y sexismo están presentes. Hay, en la actualidad, una nueva división del trabajo que pone el peso de las políticas sociales en las mujeres, en los negros y en los pobres.

Es fundamental cuestionarse por qué los gobiernos pasados y actuales no implementaron programas innovadores involucrando a las instituciones más activas de nuestra sociedad, especialmente aquellas que trabajan con grupos comunitarios, organizaciones no gubernamentales, dirigidas al empoderamiento de las mujeres. ¿Por qué no tuvieron habilidades propias o energía de acción? Las mujeres están buscando el empoderamiento y la libertad. Pero, ¿qué significa esto? ¿Empoderamiento significa no respetar las leyes promulgadas por la sociedad? ¿O puede ser entendido simplemente como la comprensión de lo que debería ser obedecido? La mujeres están buscando su

\footnotetext{
* Profesora y Dra. del Curso de Relaciones Internacionales del Centro Universitario de Brasilia (UniCEUB). Coordinadora del Núcleo de Estudios sobre Género, Conflictos Étnicos y Macro Economía (NEGEM).
} 
libertad, su renta personal, su ingreso en carreras políticas, y expandiendo su canales de comunicación.

Lamentablemente, los ciudadanos de América Latina no fueron contemplados con políticas sociales amplias. En Brasil, durante años y años, los gobiernos limitaron el acceso de los pobres a una cultura formal, negándoles el derecho a una alfabetización básica, siguiendo una política adoptada sistemáticamente y durante un largo período por las familias poderosas de los "coroneles" del Noreste, que controlaban no sólo la economía, sino la política de la región ${ }^{1}$. ¿Cómo podremos empoderar a las mujeres? ¿Qué tipo de políticas deberán ser implementadas por los gobiernos para beneficiarlas?

\section{Pobreza y exclusión social}

Brasil tiene una gran parcela de su población viviendo con una renta que no es suficiente para cubrir sus necesidades básicas. El principal determinante de la continuidad de la pobreza en Brasil parece ser, en las palabras de Sônia Draibe (2002) "que los gobiernos bajo la fuerte presión internacional habrían optado radicalmente por un lado de la balanza, el del ajuste económico y fiscal. Al hacerlo, habrían dado significativos pasos en dirección al desmantelamiento del antiguo Estado de bienestar social. En el caso latinoamericano, del antiguo y embrionario Estado de bienestar social gestado en algunos pocos países de la región". Sin embargo, Draibe muestra que el "desmantelamiento del Estado, tal como era esperado por algunos, no se está dando, en sus programas sociales, está ocurriendo "un movimiento de inflexión gradual del modelo pretérito de protección social, verificado sobre todo en el plano de las instituciones de políticas y programas, a través de la introducción o refuerzo de por lo menos tres características: la descentralización, los nuevos parámetros para la asignación de recursos y la redefinición de las relaciones público-privado en el financiamiento y en la provisión de bienes y servicios sociales. La nueva institucionalidad de las políticas sociales, que de allí emerge, se caracteriza aún por una expansión y multiplicación de los mecanismos participativos y, en gran parte de los programas, por el refuerzo del papel regulatorio estatal" (Draibe: 2002: 2-3).

Frente a esta política de ajuste económico, se hizo cada vez más necesario el contrapunto de una política de combate a la pobreza, en la cual una de sus caras es el crédito popular para los excluídos.

\footnotetext{
1 Ver: Josué de Castro, Geopolíticia da Fome (O dilema brasileiro: pão ou aço) (10. ed. Rev. Rio de Janeiro: Antares, 1983); Celso Furtado, Teoria e Política do DesenvolvimentoEconômico(Cia. Editora Nacional, 1979),con su economía del desarrollo, Gilberto Freire, Casa Grande e Senzala, que trae a la luz la cuestión de la división social; y Paulo Freire, con su Pedagogia dos Oprimidos (Pedagogy of the Oppressed, New York: Herder and Herder, 1972), Las Iglesias, la educación y el proceso de liberación humana en la Historia (Buenos Aires: Asociación Editorial Aurora, 1974), porque abogaba por un cambio "consciente" en la sociedad. Él era un activista para los pobres, un precursor, siempre enseñando a las clases más excluídas a leer y escribir. Desde el princípio, demostró solidariedad en relación con el ser humano y una aproximación política defensiva. Paulo Freire creó los Círculos Culturales en Recife, estado de Pernambuco, dirigidos a los trabajadores de las clases más pobres, que se encontraban eventualmente para discutir temas específicos y de su interés. Las discusiones eran coordinadas por un profesor, que también definía la manera en que aquel tópico, que había sido elegido ppor los trabajadores, debería ser enfocado. Ver: Freire-Dowbor, Paulo Freire, a precursor. In: Texts from Brazil n. 7. Brasília: Ministry of Foreign Relations, 2000, p. 16-17; Sonia A. Álvarez: 1990.
} 
En las últimas décadas fue creciente la incorporación de las mujeres al mercado de trabajo tanto urbano como rural, en los más diferentes niveles de calificación y escolaridad. Las mujeres participan directamente de la producción, pero continúan siendo responsables de la ejecución de los quehaceres domésticos, lo que les acarreta la sobrecarga de una doble jornada de trabajo. La problemática social de la doble jornada es vivida de forma muy clara por las mujeres de los estratos populares en la familia, donde el papel desempeñado por ellas, en la búsqueda de un trabajo fuera del hojar, como empleada doméstica, niñera, revendedora, muestra su lucha por la supervivencia y tiene como valor agregado que su responsabilidad en relación con los trabajos domésticos es un peso muy alto. En este contexto, la búsqueda de la viabilización de una actividad remunerada podrá representar la ampliación de su vivencia personal, hacer que venzan los prejuicios y permitir que puedan conciliar el trabajo y las responsabilidades familiares.

La entrada en la esfera pública externa, ocupada anteriormente por los hombres en proporciones más altas, permite que las mujeres vislumbren, también para ellas, nuevas oportunidades remuneradas, un negocio sólo suyo, como la apertura de una venta de agua de coco, agua mineral, de bijouterie, de flores o ropa, transponiendo las líneas anteriormente delimitadas por los hombres. El gerenciamiento de un micro negocio, la comprobación de su capacidad laboral y administrativa, el éxito y las ganancias, harán que busquen una mayor emancipación económica, esperando la consolidación de su negocio. A partir de allí, se hace posible que recurran a los órganos públicos y privados, a los órganos formales del sistema financiero para regular su microemprendimiento, confiadas en su éxito, ampliando su espacio en el mercado y buscando líneas de crédito. Gran parte de su éxito puede depender del modo en que consigan articular sus negocios y cómo logren su inserción en la red familiar o de parentesco.

Si en la actualidad, las mujeres participan activamente de la esfera pública (formal e informal) del trabajo, instituyéndose una novedad frente a los espacios y tiempos de la predominancia de un Brasil rural, la realización del trabajo doméstico, para la familia, ejecutado por las mujeres, nunca las eximió de la participación en el progreso material de la familia. Las mujeres siempre trabajaron, desempeñando un sin número de tareas indispensables para la supervivencia y el bienestar de todos los miembros de la familia. El trabajo en el interior de la casa y en el campo, externa, siempre fue fundamental para evitar la total privación del grupo familiar. Es un panorama de privación, de la persistencia de la segregación en un espacio exclusivo, acompañada de dificultades al intentar vislumbrar nuevos rumbos en el campo profesional.

En la búsqueda de un trabajo fuera del hogar, las mujeres están tratando de potencializar su gestión empresarial y mejorar su autoestima. Ese nuevo modo de vida impone a las mujeres una reorganización social, una reestructuración "formal" en el centro urbano, donde su cotidianidad se inserta en exclusiones y en objeto de estrategias de recusación. Es desenraizarse, modelarse a un nuevo ambiente regido por una determinada lógica atribuida a la nueva condición de revendedora, vendedora de agua de coco, o de agua mineral, siendo por eso llamadas trabajadoras a domicilio o externas. El trabajo remunerado externo es visto por las mujeres como una estrategia posible de emancipación de su papel subalterno en la familia (Bruschini et al: 1998: 277).

El trabajo doméstico, en la acepción de Marilena Chauí, aparece como si fuese un trabajo para la familia y no como un trabajo de la casa y, por lo tanto, un trabajo que ya 
es social. Las tareas domésticas ejecutadas por la mujer significan el porcentaje de por lo menos un salario mínimo; éste deberia ser el pago, si efectivamente le fueran atribuidos valores a la realización de servicios que la familia tendría que comprar en el mercado externo. Es la rutina de las mujeres. Son tareas realizadas "gratis" en el hogar por años y años (Bruschini et al.: 1982: 10). Esa población considerada "inactiva" se encuentra efectivamente ocupada, o sea, trabajando en la producción doméstica no remunerada. Trabajando mucho más que el hombre, cumpliendo una jornada de trabajo doble. Además, la mujer participa de actividades productivas, cosiendo, bordando, haciendo dulces y galletas, hasta lograr insertarse, la mayoría de las veces, en el sector secundario. El trabajo productivo no remunerado ejecutado por las mujeres há sido excluido de los principales análisis, principalmente porque los economistas asumieron que, tanto la reproducción como el trabajo de gerenciamiento de recursos humanos desempeñados por las mujeres, deben continuar siendo ejecutados ellas, independientemente de la manera como los recursos de mercado deban ser reasignados. El trabajo no remunerado de las mujeres muestra estar disponible sin el menor problema, de forma infinitamente elástica, permaneciendo al alcance de las manos, para cubrir los períodos estacionales en los que la economía demanda una mano de obra extra y otros recursos necesarios para la supervivencia durante los momentos de escasez familiares (Afshar \& Dennis 1996: 6-7).

Elisabeth Lobo (1992:257) comprende que "estudios que asocian familia y trabajo y que se tornan corrientes en el Brasil de los años setenta y ochenta hacen un aporte fundamental, pero alerta sobre el peligro de que esta reflexión tiende a privilegiar el presupuesto familiar y su proyecto estratégico, subsumiento integralmente a las mujeres como actores sociales (...). el problema consiste en la visión estructural sobre la naturaleza del trabajo femenino, lo que impide la problematización de las formas históricas y culturales de la división sexual del trabajo y las fija en términos de reproducción de los roles sociales".

Conscientes del alerta de Elisabeth Lobo, entendemos que el análisis de los "roles sociales" tradicionales entre hombres y mujeres y el de sus transformaciones debe ser hecho a la luz de la utilización de la perspectiva teórica de género (Machado: 1994, Scott: 1990), que permite indicar que toda y cualquier división sexual del trabajo y configuraciones de papeles sexuales no es la atribución de roles a sexos predeterminados, sino es consecuencia de una relación social simbólica previa que instituye significados de géneros: femenino y masculino, "sin establecer una mecánica de determinación" y que, "en este sentido, la división sexual del trabajo es uno de los muchos locus de las relaciones de géneros" (Lobo: 1992: 260).

Como destaca Bruschini (1998: 277), la idea de que la raíz de la subordinación de la mujer está en su exclusión del mundo productivo era el fundamento del feminismo, tanto en su versión liberal como en aquella de inspiración marxista, constituyendo una referencia importante para transformar el trabajo femenino en problema teórico. Lavinas (1992: 226) enfatiza que en el primer caso, la fuerza de trabajo femenino estaría perdiendo su "especificidad" en el mundo capitalista de producción, conquistando mayor movilidad, lo que parece invalidar el paradigma explicativo de la sobredeterminación de la inserción familiar sobre la inserción profesional. Por eso mismo, el ciclo vital de la familia se estaría tornando inadecuado como instrumental teórico para pensar las desigualdades entre sexos en la familia y explicar, por extensión, la participación diferenciada de hombres y mujeres en el mercado de trabajo. Las mujeres cada vez más 
se constituyen en población ocupada y sus niveles de escolaridad superan a los masculinos.

Sin embargo, si la exclusión de las mujeres del mercado de trabajo en función de su inserción en el trabajo doméstico parece decrecer, en gran parte, siendo superada por la entrada de mujeres en el mercado de trabajo y por su creciente inserción en el mundo escolar, las diferencias salariales entre hombres y mujeres es donde parecen concentrarse los síntomas más visibles de la permanencia de las cuestiones diferenciales de género en la inserción en el mercado de trabajo y en la división del trabajo doméstico. En Brasil, el rendimiento promedio mensual de hombres con 4 a 7 años de estudios es igual a $\mathrm{R} \$$ 445,10 , mientras las mujeres perciben un salario de $\mathrm{R} \$ 245,20$, que corresponde al $55,1 \%$ del salario de los hombres. Es importante apuntar que las diferencias de salario por sexo (lo que el salario femenino representa en relación con el masculino) van del 61,15\%, en la población de hasta 3 años de escolaridad, al 55,08\% de 4 a 7 años, con índices del $56,26 \%$ de 8 a 10 años y 56,26\% de 11 años o más. En la Región Metropolitana de Salvador, foco de nuestro análisis, las variaciones son más desfavorables para las mujeres: 55,3\% (hasta 3 años), 54,38\% (de 4 a 7 años), 55,82\% (de 8 a 10 años) y $56,02 \%$ (de 11 años y más)². Además, demuestra un hiato en la remuneración de la demanda por trabajo, lo que hace ciertamente prevalecer la hegemonía de la oferta de trabajo para los hombres, pronfundizando disfunciones sociales, que consecuentemente aumentan el prejuicio entre los hombres y las mujeres en el mercado de trabajo. Castro (2003: 13) destaca: "En 2001, las familias afrodescendientes encabezadas por mujeres tenían un rendimiento domiciliario promedio de $\mathrm{R} \$ 202,00$. Las que eran encabezadas por un hombre también afrodescendiente estaban en el orden de los R\$208,60. Si una mujer blanca fuese recensada como jefe, tal indicador subiría a $\mathrm{R} \$ 481,20$. En el caso de los hombres blancosm un poco más, $\mathrm{R} \$ 482,10$. Entre las niñas afrodescendientes, de los 10 a los 14 años, el 4,5\% serían analfabetas. Las analfabetas entre las niñas blancas ascendían al 1,3\%".

El trabajo femenino no representó tendencialmente la salida del mundo doméstico o una nueva división del trabajo en el espacio doméstico, sino que pasó a focalizar la articulación entre el espacio productivo y la familia. Para la mujer, la vivencia del trabajo implica siempre la combinación de esas dos esferas, ya sea por la adaptación o por la superposición (Bruschini: 1982). Esta diferencia salarial entre hombres y mujeres parece indicar que, o el género femenino es representado por el mercado de trabajo como capaz de desvalorizar, por sí mismo, la calidad misma del trabajo; a la representación sobre género femenino es que el objetivo del mercado de trabajo es secundario en relación con las funciones domésticas, pudiendo, por eso, ser menos remunerado.

A pesar del considerable columen de actividades que se esconde bajo la rúbrica de quehaceres domésticos y que mantiene ocupadas a mujeres de todos los estratos sociales, el trabajo doméstico no es contabilizado en este tipo de relevamiento como actividad económica, ni por el Instituto Brasileiro de Geografia e Estatística (IBGE), ni por la CEPAL, ni por la OIT. Existen prejuicios en relación con el papel de la mujer en la sociedad, que tienden a clasificarla prioritariamente en su función de ama de casa. Hasta el censo de 1970, el rol de jefe de la unidad comiciliaria investigada se atribuía al hombre, aunque éste no fuese el proveedor de la familia. A partir del censo de 1980, el censista recibe la instrucción de atribuir al informante la tarea de designar a la persona que cree que ejerce el rol de jefe familiar (Bruschini: 1982). 
Actividades singulares como criar hijos, cocinar, cuidar de la casa y otras comienzan a ser valoradas por investigarodes y analistas internacionales (Álvarez: 1990; Bruschini: 1992; Castro: 1992; Craske: 1999; Lavinas: 1992; Lobo: 1992; Machado: 1998; Heilborn: 1992; Rosemberg: 1992 y Saffioti: 1992), que en sus trabajos sobre economía muestran que existe un invisible aporte de las mujeres a la renta nacional, tal como lo refleja una investigación sobre el tiempo consumido por hombres y mujeres en actividades mercantiles y no mercantiles, en 31 países industrializados revelan que el $53 \%$ del total del tiempo de trabajo en los países en desarrollo y el 51\% en los industrializados es consumido por las mujeres. Muestran también que en los países industrializados el $66 \%$ del total del tiempo de trabajo es consumido por los hombres en actividades remuneradas y el $34 \%$ en no pagas, mientras que en los países en desarrollo esa relación es de $76 \%$ en actividades remuneradas y $24 \%$ en trabajo no pago. Al tiempo que las mujeres, tanto en los países en desarrollo como en los industrializados, consumen el $34 \%$ del tiempo de trabajo en actividades remuneradas y el $66 \%$ en las que no lo son. Craske (1999: 37) señala los cambios en las estructuras domiciliarias, reflejados a partir de las nuevas oportunidades de trabajo que surgen para las mujeres y que dan como resultado mayores posibilidades de vida independiente, lo que redunda en el crecimiento de mujeres proveedoras del hogar. La crisis económica funcionó también como un factor catalizador del aumento de las extensiones familiares, en las cuales varios miembros viven juntos en la misma casa, contribuyendo con diferentes fuentes de ingresos al sustento domiciliario. En estas circunstancias, la mayoría de las veces, las mujeres mayores proveen servicios no remunerados a la familia.

A partir de estos y otros resultados, el Informe de Desarrollo Humano propone que al mensurarse la categoría trabajo se considere el número de horas que las mujeres y los hombres consumen en el mercado de trabajo, en vez de emplear el método tradicional de contar el número de participantes en la fuerza de trabajo (UNDP: $1995 \mathrm{in}$ : Bruschini: 1998: 293-294). Estos datos cualitativos presentados son relevantes para la fundamentación de la investigación, pues nos permiten calcular la importancia de entender la inserción de la mujer en el mercado de trabajo, focalizando en la articulación entre el sector productivo y la família. Ésta es la perspectiva que nos orientó para pensar y analizar las políticas públicas de micro crédito.

\section{Discriminación étnica y políticas sociales en brasil}

$\mathrm{Al}$ enfocar los lugares sociales de las mujeres en la sociedad, especialmente en aquellas que migran de la zona rural a los centros urbanos y comienzan a trabajar en el sector informal, es importante destacar que, en esa búsqueda, aun sin tener una conciencia clara de estar enfrentando un nuevo mundo con restricciones financieras, estarán tratando de hallar los agentes financiadores, en un contexto de políticas sociales.

La mudanza a las ciudades acarrea un gran número de consecuencias culturales. Las costumbres y el lenguaje se pierde o son diluidos por las migraciones y la interacción con grupos de otros estados y regiones. Las ciudades, al mismo tiempo que producen un shock, ofrecen un contacto más próximo con la "cultura global", especialmente a través de la industria del entretenimiento y de las redes de "fast-food", que presentan una singular influencia norteamericana. La globalización es reforzada a través de la velocidad en las transformaciones en tecnología, en los sistemas de información y en la hegemonía 
de las economías de libre comercio, con sus fábricas transnacionales dispersas por el mundo. Este proceso económico no implica la homogeneización de la cultura, al punto de que no existan más diferencias regionales o nacionales. Hay, sin embargo, una fertilización cruzada de culturas, que reflejan lo tradicional y lo nuevo y están en constante mutación (Craske: 1999: 27).

Brasil, como otros países de América Latina, vivió dos décadas de régimen autoritario marcado por la represión, disfrazado de democracia progresiva, en el que se evidenció el corporativismo estatal. El autoritarismo permitió un acceso mínimo de la población a la arena de decisión política, lo que tornó más difíciles las luchas de las mujeres por una subjetividad política. El legado del colonialismo muestra una sociedad altamente estratificada por jerarquías de clases, raza y género. Una elite social de "gente decente" emergió, actuando como modelo central para los pobres y las comunidades afrobrasileñas. Este legado le dio a la región una serie de características, que fueron reforzadas por la exclusión política: caudillismo, un sistema peculiar en el Nordeste, especialmente en los estados de Pernambuco y Bahía, imersos en estructuras caracterizadas por el clientelismo y el centralismo. La lucha por la inclusión política y democrática se evidenció durante las reivindicaciones por elecciones libres, huelgas y protestas populares, que se dieron en los años 1969 y 1970. La intervención militar en la política fue una característica particular en Brasil, y en los países vecinos como Argentina, Bolívia y Perú, durante el siglo XX. La política de exclusión alcanzó su momento álgido cuando el Sistema de Seguridad Nacional, comenzó a investigar y a capturar supuestos miembros de instituciones "comunistas", torturando, matando y deportando sospechosos, entre ellos a miembros de asociaciones profesionales, reduciendo o eliminando los derechos civiles y humanos.

En palabras de Álvarez (1990: 70-71) "la severa represión gubernamental de los últimos años de la década del 60 y del inicio de los 70, galvanizó un feminismo brasileño naciente en la mitad de la década del 70. Muchas mujeres que se convertirían en los núcleos organizacionales del feminismo contemporáneo en Brasil eran activistas militantes de organizaciones de izquierda y de grupos de estudiantes". Enfatiza además que "los discursos revolucionarios de la izquierda sobre justicia social y libertad, estaban imbuidos de referencias sobre la cuestión de la mujer, convocando a las mujeres a unirse a la lucha, lo que eventualmente proporcionaría una mayor conciencia y su emancipación como mujeres". Con el cierre del Congreso Nacional y la instauración del Acto Institucional $\mathrm{N}^{\circ} 5$ (AI-5), en 1968, el país vivió el período represivo más intenso de su histórica política.

La lucha del pueblo brasileño por una sociedad justa, una "Nueva República", después de veintiún años de dictadura militar, culminó con la campaña para elecciones directas en 1982, que marcó un punto crítico en la transición a un régimen civil democrático. A comienzos de los años 80, después de medio siglo de construcción institucional, de implementación y desarrollo de políticas y programas, el gobierno brasileño se mostró incapaz de completar el movimiento reformista en el área social.

Fue necesario que nuevos y emergentes movimientos sociales y asociaciones laborales y de clase se estructuraran y revitalizaran la cuestión social. Iniciativas diversificadas, en los estados y municipios, después de las elecciones de 1982, se destacaron creando y proyectando un nuevo perfil social, en la tentativa de rescatar y efectivizar una política económica y social. 
Las nuevas metas, en los años 90, proponían programas de asistencia social destinados a la población pobre y necesitada (Draibe, 2002:06-08). Sin embargo, la perspectiva de reforma del sistema brasileño de política social no se concretó durante el Gobierno Collor (1990-1993), a pesar de haber introducido en la agenda política la pauta de la modernización económica e institucional del país. Pero, en el ítem políticas sociales, "el núcleo político de este gobierno se reveló profundamente conservador, patrimonialista y populista", reduciendo el gasto social federal bajo el impacto del programa de ajuste económico y de las restricciones fiscales que de él redundaron; desarticulando las redes de servicios sociales, extinguiendo todos los programas de alimentación y nutrición en vigencia hasta 1990, con excepción del programa de merienda escolar y del Programa de Alimentación del Trabajador (PAT).

Durante este período se enfatizó el clientelismo y el sistema patrimonialista en la administración de la política social, lo que aumentó la distancia entre ciudadanos habilitados y servicios sociales, resultado de una modernización neoliberal incompleta e incompetente de Fernando Collor.

En estas metas de implementación de reformas institucionales, que integraron el eje del programa del primer gobierno del presidente Fernando Henrique Cardoso (19951998), se pretendió reestructuar los contenidos sociales de la democracia y del Estado de bienestar, pautados por objetivos de equidad y mejoramiento de la estructura de oportunidades, incluyéndose la defensa de la estabilidad macroeconómica, la reforma del Estado y la recuperación del crecimiento económico.

En el gobierno de Fernando Henrique Cardoso, la estabilidad económica fue la piedra fundamental del éxito del Plan Real, que creó un ambiente favorable para el crecimiento sostenido, generó un aumento real de los salarios para gran parte de la población y atrajo nuevas inversiones productivas (Posthuma:1999: 13).

El fundamento teórico para un análisis del desempleo y la exclusión social debe hacerse a través de un examen no sólo del contingente de trabajadores y trabajadoras, sino de las políticas sociales, cuestionando si éstas fueron establecidas en un ambiente macroeconómico estable, con la promoción del crecimiento continuo y equitativo y si hubo generación de empleo. Según Posthuma (1999: 12), durante la última década la formulación de políticas públicas para el combate al desempleo há sido una prioridad en las agendas gubernamentales, tanto en las economías industrializadas como en las en desarrollo. Dentro de estas políticas, se incluyen las dinámicas de oferta y de demanda de trabajo. Esto quiere decir que el número de personas que entrar y salen del mercado (la "oferta") y el número de vacantes abiertas o cerradas (la "demanda"), se determina en un contexto que no siempre depende, solamente, del panorama nacional.

A partir de la "oferta" y de la "demanda", se establecen la tasa de desempleo, los salarios y la productividad del trabajo. Si el contexto global es negativo, afecta a la economía en desarrollo, produciendo impactos más complejos y profundos, generando desempleo crónico. El desempleo crónico no es un problema de subdesarrollo, ni una cuestión exclusiva de los países en desarrollo, sino que se manifiesta por desafíos institucionales y sociales, que son superpuestos a ajustes económicos y tecnológicos, que no pueden ser fácilmente enfrentados de la misma forma que en los países industrializados (Posthuma (1999: 12).

El número de personas que cada año entran y salen del mercado de trabajo dependen de dos grupos de factores. El primero es la tendencia demográfica del país. El 
segundo, el desempeño de la propia economía. La elevada tasa de crecimiento de la población brasileña en el pasado, se há reflejado profundamente en el presente, a pesar de que actualmente esta tasa viene decayendo, pero ha dificultado el crecimiento de la oferta de nuevos trabajadores. En el futuro, con la disminución de la presión sobre el mercado de trabajo, no se sentirá cuánto el crecimiento demográfico perjudica a la oferta de trabajo.

En segundo lugar, se discute el efecto de la globalización. Son sus sistemas de producción, los cambios tecnológicos y la intensificación de la competencia, los que han desencadenado profundas transformaciones en el mundo del trabajo y aumentado la exclusión social ${ }^{2}$.

El crecimiento de la productividad del trabajo depende de una mejor calificación de los trabajadores, que permite la producción de bienes de mayor calidad, utilizando menos esfuerzo por parte de esos mismos trabajadores. Solamente a través de ganancias sustanciales de productividad y aumento de salarios reales es que se desarrollarán los grandes mercados de masas en el mundo. En verdad, el problema de la pobreza es derivado de la disponbilidad de un patrimonio muy limitado, incapaz de permitir la venta de un volumen significativo de bienes y servicios en el mercado, y cuando esa venta efectivamente ocurre, el precio recibido por el pobre es muy bajo.

¿Y cómo el pobre va a poder vender su trabajo? ¿En qué circunstancias? La desigualdad de "renta" y la desigualdad de "oportunidades", especialmente en Brasil, han sido desde mucho asociadas a diferentes análisis en lo que concierne a la justicia social. Bourguignon (2003: 2) especifica que "el primero de esos conceptos se refiere a la distribución de ese producto conjunto de esfuerzos desempeñados por una persona y las circunstancias particulares bajo las cuales esos esfuerzos son realizados. En la mayor parte de los casos, están ligados a la desigualdad de "renta"'.

Pero, ¿cómo una persona puede controlar esa situación? Existe una heterogeneidad de circunstancias vividas por cada ciudadano, e imbuídas de hechos que alcanzan al individuo sin que él los controle; catástrofes naturales, desgracias inesperadas, que cortan el destino de cada uno como enfermedades infectocontagiosas, y que afectan al pobre en su totalidad. ¿Cómo los pobres van a lograr separar esas "circunstancias" de los "esfuerzos"? Tanto unas como los otros, se muestran cada vez más agudos en los países en desarrollo, como si fuesen un arma de doble filo.

La tasa de desempleo se muestra más elevada entre las mujeres que entre los hombres. Especialmente, en lo que concierne al trabajo implicado en unidades de supervivencia, en las cuales las tareas de las mujeres - domésticas, o en el sector público de la economía - se insertan de formas variadas, según el estrato social. La situación es mucho más grave en el campo que en el área urbana. En el campo, el proceso de individualización del trabajador aún se está desarrollando. Hay una evidencia clara de una gran masa de desempleo entre los hijos (10\%), más que entre los jefes de familia

\footnotetext{
${ }^{2}$ Las consecuencias del neoliberalismo en América Latina ya están bien demostradas por las crises brasileña y argentina; en este sentido,la autoridad del Fundo Monetário Internacional, principal instrumiento de consolidación de las políticas neoliberales, se vío abalada por su inépcia en solucionar la succesión de crises internacionales iniciadas en Ásia en 1997, y esas mismas crises abalaran la creencia dogmática en la globalización como una panacea para el desarrollo económico. Para mayores detalles a ese respeto, ver: "A lógica perversa do acordo com o FMI", de Alex Jobim Farias, Pedro Quaresma e Júlio Miragaya, in: Democracia Viva No 19, Nov 2003/Dez 2003, p. 28-34. Ver también: Pesquisa nacional para amostra de domicílios 2001: "Rendimento médio da população ocupada, em reais, por grupos de anos de estudo e sexo, segundo as Grandes Regiões, Unidades da Federação e Regiões Metropolitanas”, 2001, Rio de Janeiro, IBGE, 2002.
} 
(4\%) y los cónyuges, como lo indican datos del IBGE de 2002/2003. Cuando esas familias deciden marcharse a los grandes centros urbanos van a trabajar en el sector informal de la economía.

Son múltiples las causas de la informalidad en Brasil; una de ella, los incentivos generados por el sistema de seguridad social; otra, la legislación laboral, y; finalmente, las peculiaridades de las pequeñas y microempresas, que concentran un gran número de trabajadores informales. Mercado informal significa que la responsabilidad de los problemas en América Latina no es de la economía informal y sí del Estado, y que este tipo de economía es nada menos que una respuesta popular espontánea y creativa ante la incapacidad estatal de satisfacer las necesidades más elementales de los pobres.

Indubitablemente, el mayor desafío es combatir una y todas las iniquidades sociales, combinando, por lo tanto, políticas focalizadas y universales, estableciendo un nexo entre diferentes movimientos sociales y sin perder la perspectiva político-crítica sobre la sociedad estructurada en clases sociales. No se puede, todavía, aceptar los datos estadísticos gubernamentales que maquillan los altos índices de desempleo en Brasil.

\section{Análisis comparativa con la cuestión de género en bolívia}

La historia de los pueblos de Bolívia, cuya evolución se nos presenta como una de las más complejas y fascinantes, muestra que había una sociedad creada por conquistas imperiales y adaptaciones indígenas, una nación dominada por los pueblos campesinos de origen precolombina, pero con plena participación en la economía mundial.

En las luchas nacionalistas y revolucionarias en Bolivia, en la década del '70, se verifica una vigorosa formación sindical, teniendo como partícipes a los trabajadores mineros, en un ambiente en que las demás clases sociales parecían dispersas y escasamente cohesionadas.

La falta de relevancia de la participación femenina ${ }^{3}$ marcará a la nación como una cuestión de género, que se insertará en una teoría general de la dominación.

La década de veinte fue un período en el cual otros miembros de la elite comenzaron poco a poco a adoptar posiciones no tradicionales. En 1920 se creó el primer Partido Socialista local, y en 1921 se fundó el Partido Socialista Nacional, que aunque compuesto por un pequeño grupo de intelectuales y con apoyo mínimo por parte de los trabajadores, comenzó a debatir problemas básicos, como la esclavitud indígena, el reconocimiento legal del gobierno comunitario indígena y los derechos laborales y femeninos.

\footnotetext{
${ }^{3}$ La mujer considerada como minoría social, es explicada por Jurbert: "Minorías sociales no son vistas más como desvientes, sino como grupos que tienen posibilidades de efectuar transformaciones sociales, en la medida en que no sólo transgreden las normas vigentes, como también, en el caso de minorías activas, intentan cuestionar su validez o legitimidad. La sobrevivencia del sistema depende de su capacidad de transformarse y, en ese aspecto, las minorías activas posibilitan la ocurrencia de cambios sociales. En la medida en que tales minorías pasan a ser estudiadas como grupos sociales que no emergen de relaciones interpersonales, sino de factores históricos y culturales que preceden y condicionan las relaciones interpersonales de sus integrantes, el hecho de pertenecer a ese grupo es, de cierta forma, impuesto a sus miembros por el consenso cultural (criterios externos) e igualmente por la percepción de las características que comparten con los demás miembros de sus grupos (criterios internos). In: Jurbert, Marise Becerra. A Identidade Social, as Relações Intra e Intergrupais e a Influência Social de Feministas no Rio de Janeiro, tesis de doctorado presentada al Instituto de Psicología de la Universidad de São Paulo, San Pablo, 1989, p. 4
} 
La cuestión de género y los derechos laborales, aunque fuesen ideas nuevas y revolucionarias en el contexto boliviano, ya eran considerados como parte de la tradición política marxista, bien asentada y más radical, en todos los países vecinos de Bolívia, incluyendo Perú.

Bolívia constituía un ejemplo clásico del sistema latifundiario latinoamericano; la extrema desigualdad en la división de tierras se mostraba imprescindible para controlar a la mano de obra campesina. Gracias a su dominio por la fuerza, los latifundistas controlaban con éxito el acceso a la totalidad de las mejores tierras de todas las regiones del país. De esta forma conseguían mano de obra barata, ofreciendo tierra a cambio de prestaciones de trabajo, a cambio de trabajo libre en el interior de las instancias. Los trabajadores indígenas sin tierra obtenían el usufructo de parcelas de los latifundiarios, podían llevar semillas, herramientas, y en algunos casos también animales para el cultivo de los campos, que al concluir dejaban al propietario con escaso aporte de capital. Les cabía a los indígenas, inclusive, el transporte de la cosecha final.

En ese sentido, con los mercados agrícolas protegidos, incentivos y capital, las inversiones hechas por los estancieros con sus propiedades eran mínimas. Se suma a esto, el hecho de que, la mayoría de las veces, los estancieros ejercían una posición ausente, predominante en todas las regiones rurales, viviendo en los centros urbanos y ejerciendo profesiones urbanas. El resultado de todo este mecanismo se traducía en el empleo de una tecnología rudimentaria y el uso de semillas de baja calidad, lo que daba lugar a una producción agrícola de primera necesidad, con calidad inferior. De este modo, el sector agrícola permanecía tan atrasado que no podía satisfacer las necesidades de la población de los centros urbanos y del resto del país.

En abril de 1952 se derrocó a los militares ${ }^{4}$, poniendo fin al aparato represivo del Estado. La distribución generalizada de armamento entre las masas populares, la creación de las milicias urbanas y campesinas y la neutralización de la policía, contribuyeron con la transformación de la realidad política, económica y social boliviana, en una revolución social de masas.

Los revolucionarios, llamados "revolucionarios a regañadientes", se vieron, de esta forma, lenta e inexorablemente forzados a reformular totalmente a la sociedad boliviana 5 .

En el segundo semestre de 1952 y, a principios de 1953, la sociedad rural comenzó a ser reestructurada de forma violenta por jóvenes radicales políticos, que atacaron todo el sistema latifundiario. Movimiento similar al "gran miedo" ocurrido

\footnotetext{
${ }^{4}$ Guevara, Walter A. llama la atención sobre el hecho de que "como en la mayoría de los países de América Latina, los militares han ejercido el poder en Bolívia, de manera intermitente, desde las épocas de la independencia" in: "Los militares en Bolívia", Nueva Sociedad, N 56-57, septiembre-octubre 1981, Caracas, Venezuela, p. 19.

5 "A imagen y semejanza de sus hermanos de las fábricas y las minas, también constituyeron milicias armadas para defender las tierras y haciendas ocupadas. Los campesinos, empero, no iniciaron allí su lucha por recuperar la tierra de sus antepasados: alzamientos campesinos los hubo en todas las épocas. Con un sentido moderno, los sindicatos campesinos se organizaron en la década del treinta, antes y durante la Guerra del Chaco y tuvieron su primer esplendor generalizado durante el gobierno nacionalista del mayor Gualberto Villarroel (1943/1946). Sin embargo, el alzamiento popular de 1952 se distingue de todos los precedentes por su profundidad y extensión a casi todo el país." Ver: ESTELLANO, Washington, "Bolivia: Hacia una segunda reforma agraria", in: Nueva Sociedad, No. 93, enero-febrero 1988, Caracas, Venezuela, p. 40.
} 
durante la Revolución Francesa, que culminó con la destrucción de los libros contables en las zonas rurales, el asesinato o expulsión de los mayordomos o propietarios y, también, con la toma violenta de las tierras. Simultáneamente, los campesinos, recurriendo a sus organizaciones comunitarias tradicionales, organizaron sindicatos campesinos y crearon milicias formales. Aunque el campo hubiese permanecido relativamente indiferente y poco afectado por los grandes conflictos de abril de 1952, al final de aquel año, se convirtió en el escenario de una violencia y una destrución tremendas.

Gracias a los esfuerzos de la Central Obrer Boliviana (COB), las comunidades fueron organizadas en sindicatos; un representante fue nombrado primer ministro de Asuntos Campesinos, mostrando su fuerza, totalmente nueva y conservadora en el escenario nacional. En virtude de los cambios implementados, el campesinato se convirtió en el bastón de los elementos conservadores del gobierno central, permaneciendo fuerte durante los posteriores veinticinco años.

La mujeres de Bolivia crearon los Comandos Femeninos del Movimiento Nacionalista Revolucionario (MNR), que se consolidaron como importantes bastiones en la lucha antioligárquica en el período 1946-1952. Las mujeres tomaron parte en los grupos de resistencia, actuaron como agitadoras y propagandistas y durante la insurrección participaron de la lucha en las calles. Como un movimiento social auténtico, la participación femenina se tornó fundamental para el $\mathrm{MNR}^{6}$, creando una organización de mujeres mineras, que se consolidó y cuya participación se tornó importante para los sindicatos mineros. Además de este movimiento, se crearon en 1962 la Unión de Mujeres de Bolivia (UMBO) y la Federación Democrática de las Mujeres de Bolivia (FDMB), ambas promovidas por la izquierda boliviana; poco después se creó la Federación Nacional de Mujeres Campesinas "Bartolina Sisa"; organización adscripta a la Confederación Sindical Única de Trabajadores Campesinos de Bolivia cuyo objetivo era la participación política y sindical de la mujer campesina a nivel nacional, y que logró consolidarse rápidamente.

El MNR fue el primero partido político que incorporó orgánicamente a la mujer boliviana en sus filas: las mujeres ingresaban en la política y hacían política a través del MNR. Las tareas de las mujeres en el partido eran, de alguma manera, "tareas típicamente femeninas": apelaciones judiciales, oficios religiosos, correos clandestinos, marchas populares, transporte de armamento, cuidado de enfermos, atención a presos, huelgas de hambre, etc.; las que solamente implicaban las que el partido destinaba para ellas $^{7}$. Se vuelve relevante mencionar que al aceptar tales incumbencias, las mujeres las

\footnotetext{
6 "Muchas de nosotras hemos llegado al feminismo a partir de una militancia en los partidos de la izquierda latinoamericana. Habíamos aprendido un estilo de militar, de organizar reuniones y participar en ellas, de definir objetivos políticos. Nuestra propia historia personal implica un cuestionamiento que empieza en el interior de los partidos, con un esfuerzo para justificarnos con nuestros camaradas, que nos tildaban - por supuesto - de pequeño burguesas", desviacionistas, europeizadas, despolitizadas, etc." Testimonio de Ana Vásquez en: "Feminismo: dudas y contradicciones", Nueva Sociedad, № 78, julio/agosto 1985, Caracas, Venezuela, p. 58.

7 "En aquella época, el MNR gobernó Bolivia, primero con Paz Estenssoro, después con Hernán Siles Suazo y, nuevamente, Paz Estenssoro. Nosotros habíamos puesto a ese gobierno en el poder, gobierno que se decía 'nacionalista y revolucionario', pero empezó a no hacer caso a lo que el pueblo decía y quería.", en: Viezzer, Moema. Se Me Deixam Falar..., Domitila: Depoimento de uma Mineira Boliviana, $11^{\circ}$ Edición San Pablo, Global Editora, 1986, p. 59. Ver también: Paramio, Ludolfo. "Lo que todo marxista vulgar debe saber sobre feminismo", en: Nueva Sociedad, N 78, julio/agosto 1985, Caracas, Venezuela, p. 80-88.
} 
cumplían siempre con estricta disciplina orgánica, como mujeres militantes. A fin de que se procesasen las tareas concretas y específicas en el ámbito del Comando Nacional Femenino, surgió un grupo de mujeres denominado "Barzolas". En realidad, el jefe del partido, Víctor Paz Estenssoro, deseaba transformar a este grupo en "una especie de policía secreta femenina". Este grupo se convirtió en un instrumento de represión hacia el cual Bolivia guarda un sentimiento de rencor, debido a actitudes negativas para con los trabajadores que reivindicaban sus derechos.

La nueva generación nacida después de 1952, a diferencia de sus padres, asimilaron el hecho de que no nacieron como siervos de un feudo y sí como hombres libres. Libertos, inclusive de los medios de producción necesarios y suficientes para generar excedentes que les permitan insertarse como productores de mercaderías en el mercado capitalista y posibilitar, de esa forma, un proceso de acumulación de capital.

El análisis del sector agrícola y la incorporación de la mujer al mercado de trabajo urbano infiere sobre el fenómeno de la migración, que se constituye como un elemento determinante. Esta migración del campesino indígena del Altiplano y de los valles, así como la posibilidad de acceso a la tierra con una extensión mínima de 50 hectáreas, proporcionó una configuración denominada "agro cruceño", en la cual se combina la producción minifundiaria con la gran producción mecanizada".

$\mathrm{El}$ aumento de la migración ha sido influenciado por las tendencias de crecimiento demográfico que, en el caso de la mujer, se ve asociado a la falta de empleos en la zona rural y a la marginalización a la que el desarrollo globalizado las condena. Las familias campesinas bolivianas están situadas en regiones alejadas de los mercados, sin vías de acceso permanentes y sin energía eléctrica. Los grandes productores de algodón, caña de azúcar y ganado, y los productores de soya, sorgo y arroz fueron forzando a los colonos a que se transformaran en mano de obra asalariada.

\footnotetext{
${ }^{8}$ María Barzola fue una célebre mujer minera que encabezó la marcha en defensa de las libertades sindicales y de la economía popular, en la cual perdió la vida el día 21 de diciembre de 1942, en la denominada "masacre de Catavi", en: Ardaya, Gloria, Participación Política y Liderazgos de Mujeres en Bolívia, Centro de Información y Desarrollo de la Mujer (CIDEM), PROLID-BID, Primera Edición, La Paz: Abril 2001, p. 117. "La centralidad política o, si se quiere, la capacidad de articulación social del proletariado minero boliviano es incontrastable. Desde hace cuatro décadas, sus victorias y derrotas lo son también del conjunto de las clases subalternas. No extraña entonces que los héroes mineros traspasen su propio ámbito para convertirse en representaciones populares. Mas, en la imaginería minera predominan los varones. La excepción es María Barzola, muerta en la masacre Catavi (1942). ¿Corresponderá esto a las imágenes reales? O, por el contrario, forma parte de la invisibilidad histórica de la mujer que reclama Sheila Rowbotham. La cara oculta de la historia oficial-estatal e, incluso, la sindical, reduce los acontecimientos sociales. Allí, las mujeres gentes sin historia, son subsumidas en la acción colectiva de los trabajadores. Ellas sólo acceden a la historiografía cuando se destacan por su valor o heroísmo, sus acciones normales no merecen un mayor recuento." Ostria, G. R. "Las compañeras del mineral", en: Nueva Sociedad, N$^{\circ}$ 93, enero-febrero 1988, Caracas, Venezuela, p. 177.
}

\footnotetext{
${ }^{9}$ Estellano infiere sobre este nuevo proceso de concentración de la propiedad de la tierra en Santa Cruz, informando que: "De los 9 millones de hectáreas distribuídas hasta 1980, unos 5 millones corresponden a 1.361 personas individuales con extensiones superires a las 5 mil Has por persona. Mientras que 60 mil campesinos sólo poseen 900 mil Has, o sea, un promedio de 15 Has por familia" en: ESTELLANO, W., "Bolivia: Hacia una segunda reforma agraria”, op. cit., p. 44.
} 
Los campesinos, en la actualidad, intentan mantenerse unidos a viejas tradiciones de vida, funcionamiento y producción comunitaria. En verdad, resisten al neoliberalismo de Paz Estenssoro, retornando a las prácticas precapitalistas de producción, lo que para la economía política ortodoxa es una aberración incomprensible.

Las políticas económicas deberían activar la producción de pequeños y medianos propietarios, sin provocar una mayor dependencia externa, sin chocar con las prácticas tecnológicas tradicionales, con el objetivo de proporcionar un aumento de la demanda por parte de los consumidores y estimular la economía.

\section{Conclusiones}

La historia nos muestra una América Latina donde los líderes políticos siempre fueron hombres que conquistaron y reconquistaron el poder, generaciones masculinas que cerraron las puertas a las mujeres. A pesar de las restricciones sociales impuestas a las mujeres, ellas están ganando más autoconfianza, más control directo sobre sus propias "opciones de vida". Se presupone que las mujeres están logrando "empoderamiento" en el hogar y acceso al poder económico. Aunque no sea totalmente verdad, ganarán alguna influencia en la esfera política, pero la producción historiográfica existente se refiere muy poco a las sociedades en las cuales las mujeres ejercieron de hecho una grande influencia en el área política.

Las mujeres en América Latina aún no lograron alcanzar una autoridad política de "power over" para cambiar las cosas. En vez de eso, registraron victorias específicas en esferas restringidas, que fueron rotuladas como "power to". Las mujeres fueron capaces de promover una conciencia individual, tanto entre los hombres como entre ellas mismas e impulsaron algunas modestas reformas. A pesar de las conquistas evidenciadas, hay una desconexión entre el activismo femenino y sus conquistas prácticas. En síntesis, los valores sociales patriarcales ocultos en la sociedad brasileña y boliviana impidieron de forma inequívoca la participación femenina. 


\section{Bibliografía}

AFSHAR, Haleh and DENNIS, Carolyne. "Women, Recession and Adjustment in the Third World: Some Introductory Remarks", in: Haleh Afshar and Carolyne Dennis (eds.), Women and Adjustment Policies in the Third World, Basingstoke: Macmillan, 1992.

ALVAREZ, Sonia E.. Engendering Democracy in Brazil: Women's Movements in Transition Politics, Princeton University Press, 1990.

BOURGUIGNON, François, FERREIRA, Francisco H.G., and MENÉNDEZ, Marta. Inequality of Outcomes and Inequality of Opportunities in Brazil, World Bank Research Working Paper 3174, December 2003.

BRUSCHINI, Maria Cristina A. e ROSEMBERG, Fúlvia. “A Mulher e o Trabalho" in: Trabalhadoras do Brasil, organizadoras: Maria Cristina A. Buschini e Fúlvia Rosemberg, Fund. Carlos Chagas, Ed. Brasiliense, São Paulo: 1982.

CASTRO, Josué de. Geografia da Fome (O dilema brasileiro: pão ou aço). 10 ed. Rev. Rio de Janeiro: Antares: 1983.

CASTRO, Mary Garcia. "Alcance e Limites das Políticas de Identidade", in: Revista Democracia Viva, No. 19 - Nov/Dez 2003.

CASTRO, Mary Garcia e LAVINAS, Lena. "Do Feminino ao Gênero: A Construção de um Objeto", in: Uma Questão de Gênero, org.: Albertina O. Costa e Cristina Bruschini, São Paulo: Fund. Carlos Chagas, 1992.

CRASKE, Nikki. Women and Politics in Latin America, Rutgers University Press, New Brunswick, NJ, 1999.

DOWBOR-FREIRE, Fátima. Paulo Freire: a precursor. In: Texts from Brazil n. 7. Brasília: Ministry of Foreign Relations, 2000, p. 16-17.

DRAIBE, Sonia M. Brasil: a proteção social após vinte anos de experimentação reformista, doc. apresentado no Taller Inter-Regional "Protección Social en una Era insegura: Un Intercambio Sur-Sur sobre Políticas Sociales Alternativas en Respuesta a la Globalización", Santiago, Chile, Mayo 14-16, 2002.

ESTELLANO, Washington, "Bolivia: Hacia una segunda reforma agraria”, in: Nueva Sociedad, No. 93, Enero-Febrero 1988, Caracas, Venezuela, p. 39-50.

GUEVARA, Walter A.. "Los Militares en Bolivia", Nueva Sociedad, No 56-57, Septiembre-Octubre 1981, Caracas, Venezuela. 
HOLT, Sharon L. and RIBE, Helena. Developing Financial Institutions for the Poor and Reducing Barriers to Access for Women, 117 World Bank Discussion papers, Washington, D.C., 1991.

JURBERG, Marise Bezerra. A Identidade Social, as Relações Intra e Intergrupais e a Influência Social de Feministas no Rio de Janeiro, tese de doutorado apresentada ao Instituto de Psicologia da Universidade de São Paulo, São Paulo, 1989.

LOBO, Elizabeth Souza, "O trabalho como linguagem: o gênero do trabalho", in: Uma Questão de Gênero, org. por: Albertina O. Costa e Cristina Bruschini, São Paulo: Fund. Carlos Chagas, 1992.

MACHADO, Lia Zanotta, "Campo Intelectual e Feminismo: Alteridade e Subjetividade nos Estudos de Gênero”, Brasília: Universidade de Brasília, Série Antropologia, 1994.

MOSLEY, Paul. Microfinance and Poverty in Bolivia, The Journal of Development Studies, Vol. 37, No. 4, London: Apr. 2001, p. 101-132.

NAVAJAS, Sergio, SCHREINER, Mark, MEYER, Richard L., GONZALEZ-VEGA, Claudio \& RODRIGUEZ-MEZA. Microcredit and the Poorest of the Poor: Theory and Evidence from Bolivia, World Development Vol. 28, No. 2, The American University, Washington, D.C.: 2000, p. 333-346.

NOGUEIRA, Jorge Madeira e MACHADO NETO, José Ribeiro. "Os programas de inclusão social do GDF: avaliação de seus impactos", in: Brasília - gestão urbana: conflitos e cidadania. Aldo Paviani (org.), Brasília: Ed. Universidade de Brasília, 1999.

OSTRIA, Gustavo Rodríguez. "Las compañeras del mineral”, in: Nueva Sociedad, No. 93, Enero-Febrero 1988, Caracas, Venezuela, p. 177.

PARAMIO, Ludolfo. "Lo que todo marxista vulgar debe saber sobre feminismo", in: Nueva Sociedad, No 78, Julio/Agosto 1985, Caracas, Venezuela.

POSTHUMA, Anne Caroline. "Transformações do Emprego no Brasil na Década de 90" in: OIT - Brasil - Abertura e ajuste do mercado de trabalho no Brasil, São Paulo: Editora 34, 1999.

SEN, Amartya. Rationality and Freedom, The Belknap Press of Harvard University, Cambridge, Massachusetts, 2002.

SMITH, Peter H., TROUTNER, Jennifer L. and HÜNEFELDT, Christine. Promises of Empowerment: Women in Asia and Latin America, Rowman \& Littlefield, Publishers, USA, 2003.

VIEZZER, Moema. Se Me Deixam Falar...Domitila: Depoimento de uma Mineira Boliviana, $11^{a}$ Edição, São Paulo: Global Editora, 1986. 
ZELLER, Manfred; SHARMA, Manohar. Access to and demand for financial services by the rural poor. In: ZELLER, Manfred; MEYER, Richard L. (eds.). The triangle of microfinance: financial sustainability, outreach and impact. Baltimore: International Food Policy Research Institute; London: The Johns Hopkins University Press, 2002, p. 19-45. 